WSRC-TR-95-0232

Publication Date: July 1995

\title{
Magnetic Survey of the Risher Road Open Metal Pit Waste Unit ${ }^{(U)}$
}

Westinghouse Savannah River Company

Savannah River Site

Aiken, SC 29808

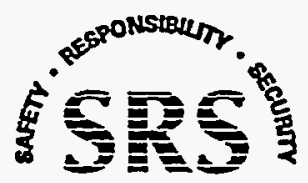

Prepared for the U.S. Department of Energy under Contract No. DE-AC09-89SR18035 


Disclaimer
This report was prepared as an account of work sponsored by an agency
of the United States Government. Neither the United States Govermment
nor any agency thereof, nor any of their employees, makes any warranty,
express or implied, or assumes any legal liability or responsibility for the
accuracy, completeness, or usefulness of any information, apparatus,
product, or process disclosed, or represents that its use would not
infringe privately owned rights. Reference herein to any specific com-
mercial product, process, or service by trade name, trademark, manufac-
turer, or otherwise does not necessarily constitute or imply its
endorsement, recommendation, or favoring by the United States Govern-
ment or any agency thereof. The views and opinions of authors
expressed herein do not necessarily state or reflect those of the United
States Government or any agency thereof.




\section{DISCLAIMIER}

Portions of this document may be illegible in electronic image products. Images are produced from the best available original document. 
WSRC-TR-95-0232

Publication Date: July 1995

Magnetic Survey of the Risher Road Open Metal Pit Waste Unit ${ }^{(U)}$

R. J. Cumbest

Site Geotechnical Services

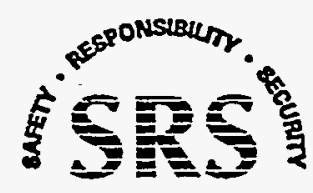

SAYANNAH RIVER SITE

Prepared for the U.S. Department of Energy under Contract No. DE-AC09-89SR18035 
This page intentionally left blank. 


\section{Contents ,}

Executive Summary ...................................................................... 1

Introduction and Scope ................................................................. 3

Magnetic Survey Concepts.............................................................3

Description of Survey Site........................................................... 5

Magnetic Survey ....................................................................... 7

Survey and Analytical Techniques .......................................... 7

Magnetic Data Set ....................................................................... 7

Discussion and Conclusions....................................................9 9

Bibliography ................................................................................ 11

Appendix A-Risher Road Magnetic Survey

Diurnal Variations............................................ 27

Appendix B-Risher .Road Magnetic Survey Data................ 31

\section{List of Figures}

Figure 1. Location of Risher Road Open Metal Pit Wáste Unit on SRS.

Figure 2. - Typical temporal variations exhibited by the total magnetic field due to diurnal variation, micropulsations, and magnetic storms on the sun (adapted from Breiner, 1973).

Figure 3. Superposition of the earth's ambient magnetic field and anomalous fields produced by induced monopoles and dipoles to produce anomalies in the total field (adapted from Breiner, 1973).

Figure 4. The relationship of magnetic inclination and declination to geographic directions on the earth (adapted from Telford and others, 1976).

Figure 5. Typical profiles of magnetic field intensity across a monopole and dipole for conditions similar to SRS. Also shown is a contour representation of magnetic field intensity over a dipole with accompanying representative profiles (adapted from Breiner, 1973). 
Figure 6. Magnetic intensity profiles across several geometric shapes of interest for magnetic field inclination similar to that of SRS (i.e. 60 degrees) (adapted from Breiner, 1973).

Figure 7. The intensity of the total magnetic field compared with the vertical gradient over a prismatic body (adapted from Breiner, 1973).

Figure 8. Model total field and vertical gradient magnetic profiles for single 55-gallon steel drums in vertical position with the top at various distances below the sensor. Profiles calculated for a total field intensity of $53220 \mathrm{nT}$ and northern hemisphere inclination of 70 degrees (adapted from Gilkeson and others, 1990).

Figure 9. Contour representation of total field anomaly calculated for a single 55-gallon steel drum in vertical position with the top $10 \mathrm{ft}$.below the sensor. Calculation based on a total field intensity of $53220 \mathrm{nT}$ and northern hemisphere inclination of 70 degrees (adapted from Gilkeson and others, 1990).

Figure 10. Contour representation of a cache of five steel 55-gallon drums in a 12-ft by 12-ft area with the top of the drums $10 \mathrm{ft}$ below the sensor. Calculation based on a total field intensity of $53220 \mathrm{nT}$ and northern hemisphere inclination of 70 degrees. (adapted from Gilkeson and others, 1990).

Figure 11. Planimetric map of the Risher Road Open Metal Pit Magnetic Survey Area. Station locations marked by " + ".

Figure 12. Color contour representation of top sensor (4 ft) magnetic survey data.

Figure 13. Color contoured representation of bottom sensor $(2 \mathrm{ft})$ magnetic survey data.

Figure 14. Color contoured representation of magnetic survey vertical gradient. 


\section{Executive Summary}

The Risher Road Waste Unit is located at the base of a small bluff (approximately $30 \mathrm{ft}$ high) composed of sand and gravel. Due to collapse of the face of the bluff a steep slope of colluvium has formed at the base. The area of investigation is located on the slope of colluvium, and is marked by the presence of two pin flags spaced approximately $25 \mathrm{ft}$ apart parallel to the bluff face. In order to investigate the presence of buried metallic material that might indicate waste containers or other trash beneath the colluvial slope a magnetometer survey was conducted in and around the vicinity of the pin flags. The survey consisted of a 5 -ft by 5 - $\mathrm{ft}$ square grid node pattem in a $40-\mathrm{ft}$ by $60-\mathrm{ft}$ rectangle.

Magnetic field and gradient anomalies were detected in the locations of the pin flags and can be attributed to the ferric composition of the pin flag shafts. Other magnetic field and gradient variations are at background levels and do not indicate the presence of buried ferric objects of any significant size. 
This page intentionally left blank. 


\section{Introduction and Scope}

The Risher Road Open Metal Pit Waste Unit is located in a large cleared area adjacent to Risher Road on SRS (Figure 1). The large cleared area occurs at the base of an approximately 30-ft-high sand and gravel bank that has a steeply sloping incline of colluvium at its base formed due to collapse of the bluff face. The waste unit was originally designated due to the occurrence of scrap metal and 5 to 10 cubic yards of lumber, which was removed in May 1989. In January 1995, a magnetic survey was conducted in a portion of the waste unit by the Site Geotechnical Services Department at the request of the Environmental Restoration Department. The survey was conducted over a portion of the colluvial slope to evaluate the possibility that the colluvium may have covered metal objects associated with the original waste unit.

\section{Magnetic Survey Concepts}

The magnitude of the magnetic field measured near the earth's surface is influenced by several factors. The main contribution to the total intensity is due to the internal magnetic field of the earth produced in the vicinity of the earth's core. However, this field is modified by the solar wind of charged particles produced by electromagnetic activity on the sun. This solar wind distorts the magnetic field produced by the earth into a teardrop shape with the blunt end pointing toward the sun. More importantly; the effect of the solar wind is to produce time variations in the total field. The earth's rotation, in effect, introduces a diurnal variation with a twenty-four-hour period. Also, superimposed on this well defined twenty-four-hour cycle are variations with no well defined period, produced by the chaotic nature of the sun's electromagnetic activity. Typically these variations manifest themselves as micropulsations on the order of less than 10 nanoTesla (nT), but significantly larger variations can be produced by magnetic storms on the sun (i.e. sunspots). The net result of these variations is illustrated in Figure 2.

The earth's magnetic field is also modified by features near the surface that produce localized spatial variations, or anomalies, in the field intensity. The use of magnetic techniques in searching for buried metallic objects is a consequence of the ability of iron and iron alloys to cause relatively large amplitude anomalies. These anomalies are produced by two effects. Some materials have properties that allow them to become magnetized in the presence of an external magnetic field. This process is called induction. The extemal magnetic field is the inducing field and the field produced by the material the induced field. The total field $(B)$ now becomes the sum of the inducing external field $(H)$ and the field produced by the material $(H)$. This relationship can be expressed:

$$
B=H+H^{n}
$$

In addition, some materials possess a magnetic field independent from any external source. This field is typically acquired at some time in the past history of the material and is called remnant magnetization. For most magnetic survey applications the magnitude of the induced field is assumed to be much greater than the remnant magnetization, and this assumption has been shown to be valid in the specific case of standard 55-gallon metal drums (Gilkeson and others, 1992).

In reality, magnetic fields are always manifest as dipoles. That is, north and south magnetic poles occur in pairs to produce dipole fields. A field line representation of a dipole and monopole field are illustrated in Figure 3. In this type of representation the density of the field lines is proportional to the field magnitude. To a first approximation, the magnetic field produced near the core of the earth can be considered a single dipole with the magnetic field lines impinging the surface of the earth at 90 degrees at the north and south magnetic poles, and parallel to the surface of the earth at the magnetic equators.

The geometric relationship of the magnetic field lines to the geographic poles is expressed by magnetic inclination and declination. Declination describes the angular relationship of the component of the field line parallel to the surface of the earth, to geographic north. The magnetic inclination expresses the angular relationship between the magnetic field lines and the horizontal (Figure 4). Although, these angular relationships change slowly due to poorly understood long term variations, the declination in the vicinity of SRS. is about 4 degrees to the west and the inclination about 65 degrees.

Although inducing bodies usually possess highly irregular shapes and sizes, they can be usefully modeled as dipoles or arrays of dipoles. In some instances, if the area of consideration is near one end of a dipole relative to the dipole - separation, the local field can be considered to be produced by a single pole, and approximates monopole behavior. The anomalous fields produced by a dipole and monopole for a magnetic inclination of 60 degrees in the northern hemisphere (i.e. conditions very similar to SRS) and their resultant effect on the total magnetic field measured near the body are illustrated in Figure 3. Notice that the anomalous field lines on the north side of the dipole are opposite in sense to the ambient field, therefore reduc- 
ing the field strength in this location. In contrast, the anomalous field lines on the south side are in the same sense, resulting in an increased field strength. The monopole exhibits similar behavior although not as extreme. This phenomena is the explanation for the asymmetrical shaped magnetic highs and lows produced by-inducing bodies at mid-latitudes on the earth. Figure 5 illustrates typical magnetic profiles that would be observed at the latitude of SRS over monopoles and dipoles in addition to a generalized contour representation of a dipole, with illustrative profiles across the contours.

Generalized magnetic field intensity profiles across more complicated shapes for an inclination of 60 degrees are illustrated in Figure 6. These profiles all exhibit the typical asymmetrical signatures along the north-south profiles with magnetic highs occurring over 'southern portions of the bodies.

The previous discussion has been presented in the context of the intensity of the total magnetic field. However, another measurement that can be very useful in interpreting magnetic anomalies is the vertical magnetic gradient, which changes much more rapidly with distance than the total field. This effect results in edge enhancement of anomalies and more effective anomaly separation (Figure 7). The vertical magnetic gradient can be determined by making measurements of the total magnetic intensity at two known elevations. The vertical gradient is then determined by the difference between the two measurements divided by their separation. The two measurements can be made by a single sensor instrument by moving the sensor between the two measurements, or by an instrument with two separated sensors.

In order to conduct a magnetic survey, magnetic data are collected at discrete intervals either along a traverse or over a two-dimensional (2-D) grid. In practice, data for 2$\mathrm{D}$ grids are usually collected as multiple traverses. Traverse data can be conveniently displayed as magnetic intensity profiles. 2-D gridded data are usually contoured and displayed as contour diagrams. Displayed in this fashion these data can be qualitatively interpreted by comparing them with profiles or contours that would be predicted from bodies of known shape and size, as presented earlier.

In addition to qualitative information, profiles and contour diagrams may also be used for quantitative analysis if the magnetic response of specific objects is known. Due to their widespread use in the past as containers for industrial materials, 55-gallon steel drums are commonly targeted during characterization of waste sites. Gilkeson and others (1992) have evaluated the magnetic response from single and multiple drums buried at different depths. The mag- netic response is provided by a model calibrated from actual measurements on a 55-gailon drum. These anomalies were calculated for a total field intensity of $53220 \mathrm{nT}$ and inclination of 70 degrees, conditions very similar to SRS.

Figure 8 illustrates model total field and vertical gradient profiles over a single drum, in vertical position, with the drum top at different depths below the sensor. If single, deeply-buried drums are the target, these profiles make clear the need to locate the sensor near the ground surface in order to minimize the distance between the sensor and drum. For sensor-drum distances greater than about $20 \mathrm{ft}$ the anomaly amplitude has decreased to values that may not be discernible from noise.

Figure 9 illustrates the contour representation of an anomaly for a single drum with its top located $10 \mathrm{ft}$ below the sensor. Also shown in Figure 9 are the station locations of a typical 5-ft by 5-ft grid over the anomaly. Note that a misfortunate placement of a 20 -ft by 20 -ft grid may fail to detect the anomaly at all, and that a badly placed 10-ft by 10-ft grid would only reveal a maximum amplitude on the order of $25 \mathrm{nT}$, which may also not be discernible from noise, and at best would offer poor resolution concerning the drum location.

Figure 10 illustrates the contour representation of a total field magnetic anomaly for a cache of five drums located in a 12-ft by 12-ft area, with the drum tops $10 \mathrm{ft}$ below the sensor. Note again a $20-\mathrm{ft}$ by $20-\mathrm{ft}$ grid may fail to detect the anomaly. A $10-\mathrm{ft}$ by $10-\mathrm{ft}$ grid would crudely resolve the anomaly. However, Gilkeson and other's (1992) modeling demonstrated that at a depth of $10 \mathrm{ft}$, if the center drum were removed, the drums on the corners would be resolved into individual anomalies. If this type of information. is required from the magnetic survey, then 5 -ft grid node separations would be needed to fully resolve the individual anomalies associated with each drum.

In addition to the above considerations other factors enter into the design of an effective magnetic survey. Although smaller grid spacings allow better resolution of anomalies, they are also labor intensive. Placing the sensor near the ground makes it much more sensitive to small, shallow sources such as metallic trash or magnetite variations in the soil. This is especially a problem for gradiometer surveys because these effects are amplified. In addition gradiometers are most effective when the sensor separation is $1 / 5$ or less the distance to the target. If the sensors are placed near the ground, this condition may not be met for shallow targets. A careful consideration of what information is needed from the magnetic survey, and the resources 
available will determine which of the aspects discussed above are most important.

\section{Description of Survey Site}

The clearing containing the waste unit occurs south of Risher Road, approximately 200 yards from a powerline. The sand and gravel bluff is located adjacent to the south border of the clearing. The eastern and western sides of the clearing are surrounded by pine forest. The area of investigation was marked by two pin flags spaced approximately $25 \mathrm{ft}$ apart, parallel to the bluff face, about half way up the colluvial slope. None of the customary orange HP waste unit marker balls were present. 



\section{Magnetic Survey}

\section{Survey and Analytical Techniques}

The magnetic survey of the Risher Road waste unit was conducted along survey traverse lines spaced $5 \mathrm{ft}$ apart parallel to the base of the bluff face. Measurements were taken at 5-ft intervals along the survey lines to yield a 5-ft by 5 -ft square grid node pattern (see Figure 11). The grid is located to give coverage to the area between and immediately surrounding the pin flags from the vertical bluff face to the base of the colluvial slope. The grid station locations were established with a transit to mark 90-degree angles and a measuring tape marked at 5-foot intervals to determine distances.

Magnetic data were collected with an EG\&G Geometrics G-856 Gradiometer with the top sensor at 1.22 meters (4 $\mathrm{ft}$ ) from ground level and the bottom sensor 0.61 meters ( 2 ft) from ground level. This configuration places the sensors near the ground to maximize the sensitivity to small near surface or deeply buried objects. This instrument has a nominal accuracy of $0.1 \mathrm{nT}$. However, high magnetic gradients (>600 nT/m) will cause the signal to be sharply degraded. In most cases this will cause the accuracy to deteriorate to $1 \mathrm{nT}$. More severe degradation can result in significant accuracy losses resulting in poor data very near large metallic objects. As a QA/QC check and in order to determine diumal variations a single station was occupied several times during the survey Appendix A).

The data were downloaded from the magnetometer through a RS-232 port to an IBM PC Model 70. After downloading, the data were assigned coordinates and diurnal corrected with MAGLOC, software provided by EG\&G. Further data display and processing, including gridding and contouring were accomplished with software provided by GEOSOFT Inc. Gridding of the data was accomplished with BIGRID which is specifically designed to grid line data and enhance trends. The data were filtered with a 20-ft low pass filter along each traverse line before gridding. This allowed very effective attenuation of wavelengths of $5 \mathrm{ft}$ or less in the data in the traverse direction. Magnetic gradients were calculated by subtracting the top sensor reading from the bottom sensor and dividing by their separation. Since the top and bottom sensor readings are taken at a relatively short time scale (approximately 3 seconds) relative to diumal variations the gradient is calculated from the data before diurnal correction. The data for the survey are tabulated in the Appendix B.

\section{Magnetic Data Set}

The magnetic survey data are displayed in Figures 12 to 14. Magnetic field values for the top sensor ( $4 \mathrm{ft}$ height) in general range from $51560 \mathrm{nT}$ to 51580 . The exceptions occurring at survey stations near the pin flags and a small dipole anomaly centered at grid coordinate $(35,25)$. The data also show a prominent northwest - southeast corrugation along the data acquisition traverse lines.

The data for the bottom sensor ( $2 \mathrm{ft}$ height) show background variations from approximately $51550 \mathrm{nT}$ to 51570 nT. Exceptions to this again occurring near the pin flags. Note that for the bottom sensor that the dipole seen in the top sensor at grid coordinates $(35,25)$ is not as prominent. The bottom sensor data also show traverse parallel corrugations.

The vertical gradient data as expected are nosier than the total field measurements for the top and bottom sensors. Vertical gradient background values range from $-7 \mathrm{nT} / \mathrm{ft}$ to $8 \mathrm{nT} / \mathrm{ft}$. Exceptions to these backgrounds again occur near the pin flags.

In summary magnetic field and gradient anomalies occur associated with the pin flags and at grid node $(35,25)$. The dipole anomaly at $(35,25)$ is stronger in the top sensor data and not significantly above background. All data sets show corrugations along the traverse directions. 



\section{Discussion and Conclusions}

The magnetic survey data for the Risher Road Open Metal Waste Unit show anomalous values near the two metal pin flags that were used to mark the location of the survey area. A significant dipole anomaly is present in the top sensor data but is not as well developed in the bottom sensor data. This fact and the size of this anomaly in comparison to the anomalies generated by the pin flags would indicate that this is due to natural variation in the soils or that it represents a very small ferric object (smaller than a pin flag shaft). The corrugations in the data result from the unresolved diurnal correction that is on the same order of magnitude as the natural background variations. These observations indicate that no buried ferric objects of any significant size are present in the magnetic survey area. 
This page intentionally left blank. 


\section{Bibliography}

Breiner, S. Applications Manual for Portable Magnetometers, Sunneyvale, Califomia 94084 (1973).

Gilkeson, R. H., Gorin, S. R., Laymon, D.E. (1992) Application of magnetic and electromagnetic methods to metal detection. Proceedings of the Symposium on the Application of Geophysics to Engineering and Environmental Problems, v.1, p.309-328.

Telford, W. M., Geldart, L. P., Sheriff, R. E., Keys, D. A., (1978) Applied Geophysics, Cambridge Ụniversity Press, 860p. 



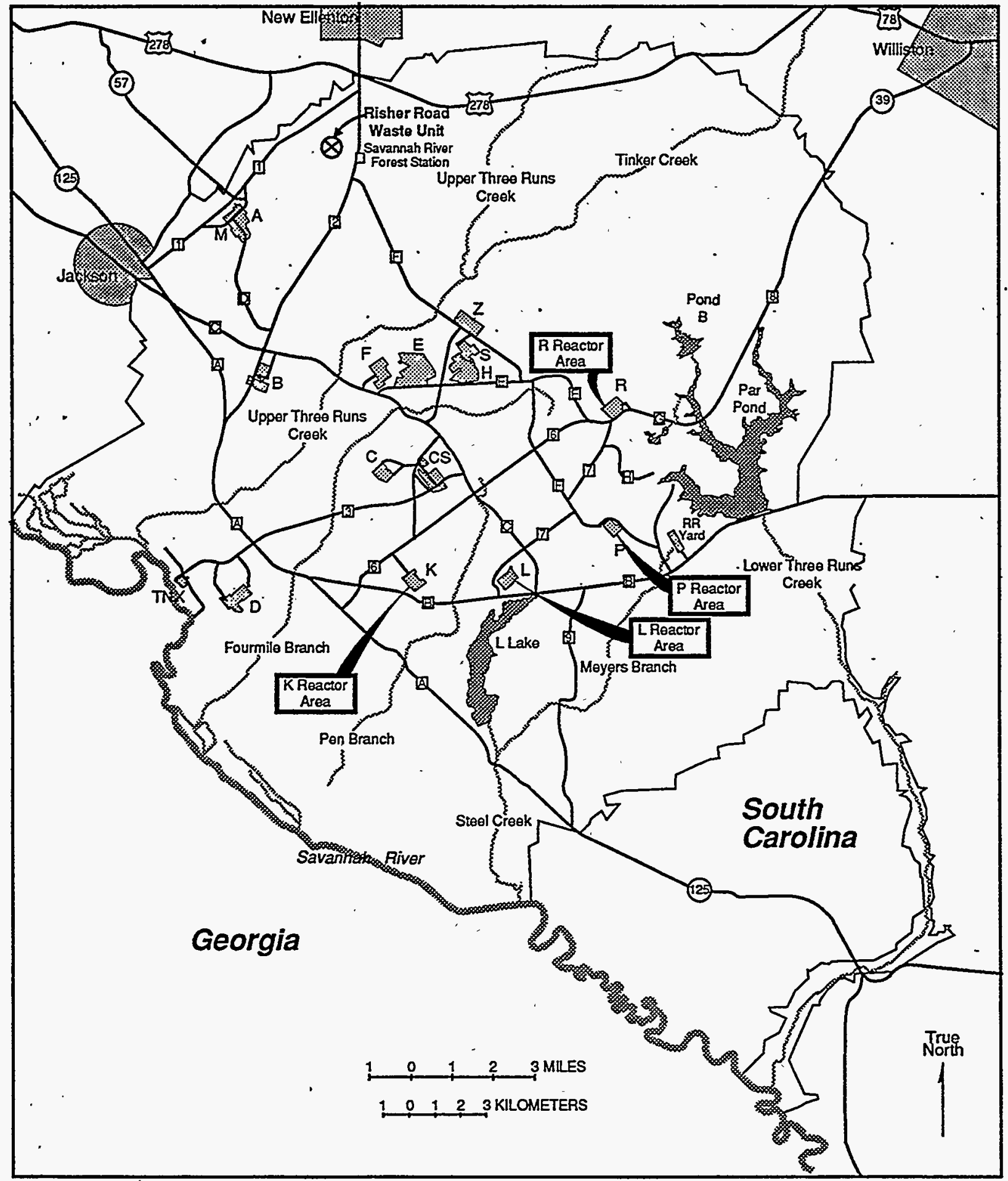

Figure 1. Location of Risher Road Open Metal Pit Waste Unit on SRS.

95X02292.10.All 


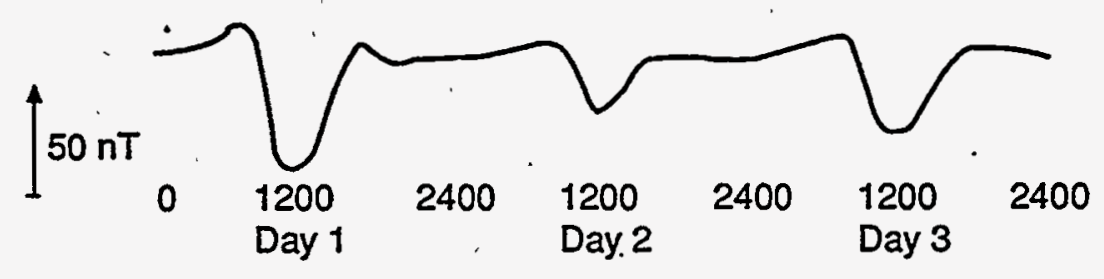

- Diurnal Variation

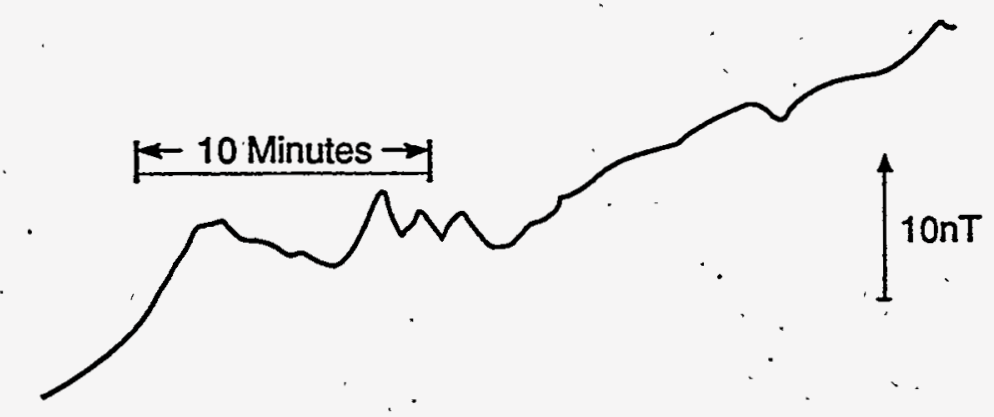

Micropulsations

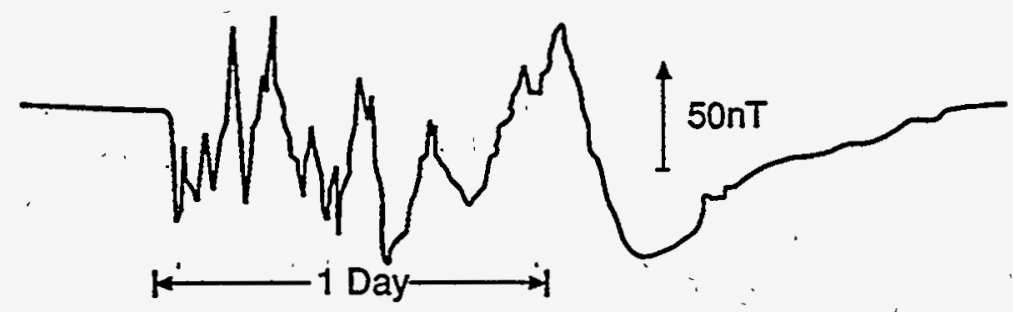

Magnetic Storm

95X02292.08.AlL

Figure 2. Typical temporal variations exhibited by the total magnetic field due to diumal variation, micropulsations, and magnetic storms on the sun (adapted from Breiner, 1973). 

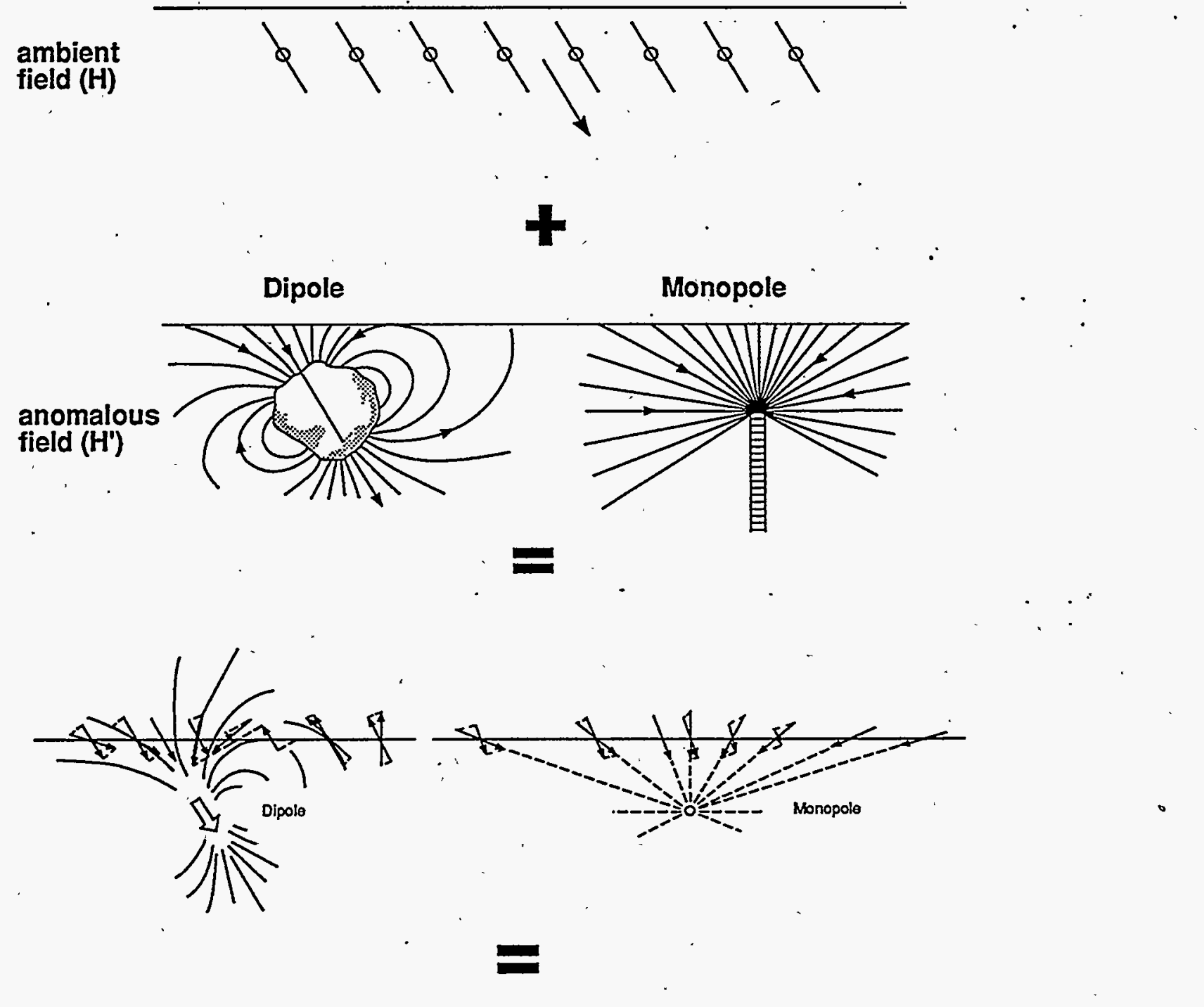

total
observed
field (B)

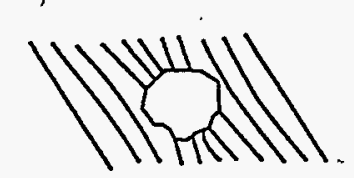

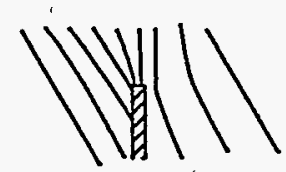

95X02292.07AlL

Figure 3. Superposition of the earth's ambient magnetic field and anomalous fields produced by induced monopoles and dipoles to produce anomalies in the total field (adapted from Breiner, 1973). 


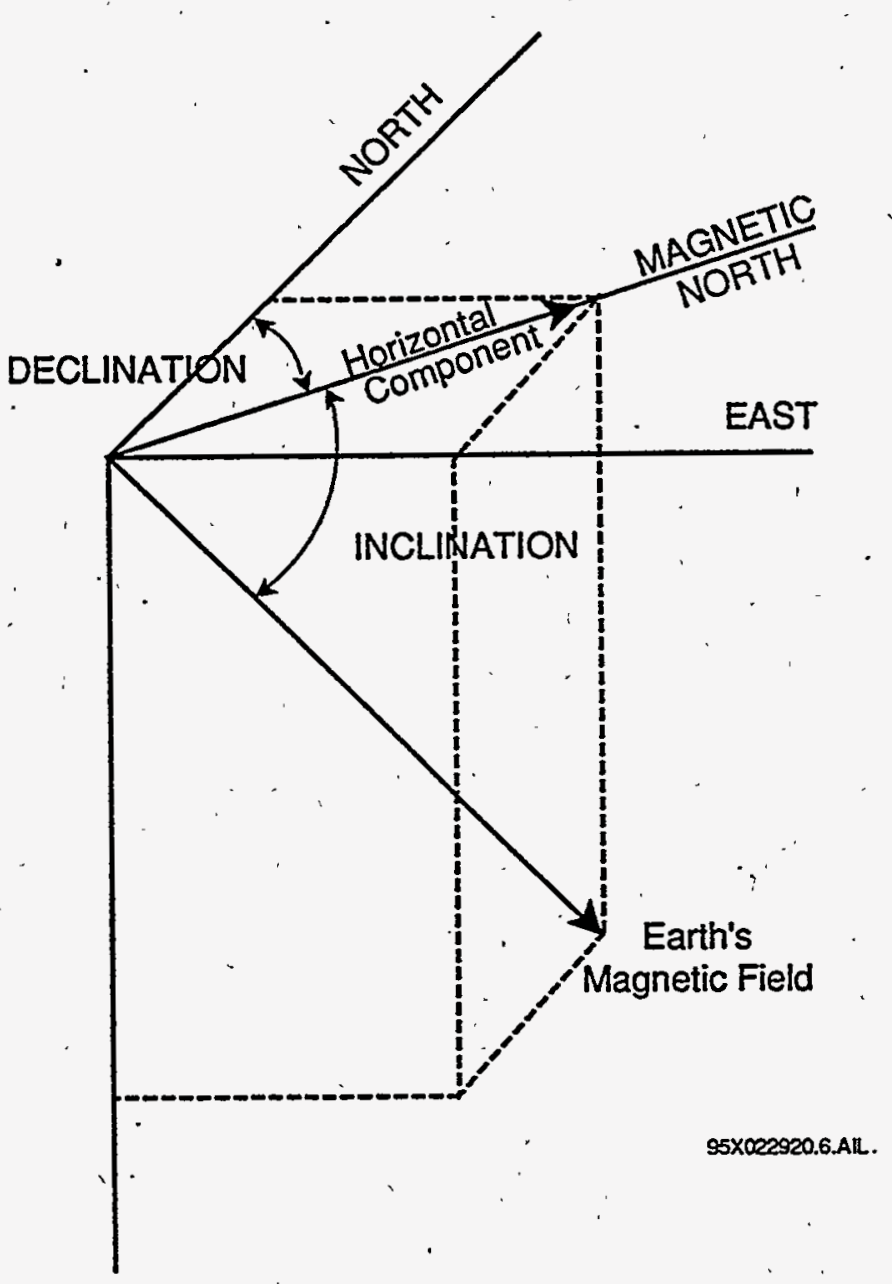

Figure 4. The relationship of magnetic inclination and declination to geographic directions on the earth (adapted from Telford and others, 1976). 

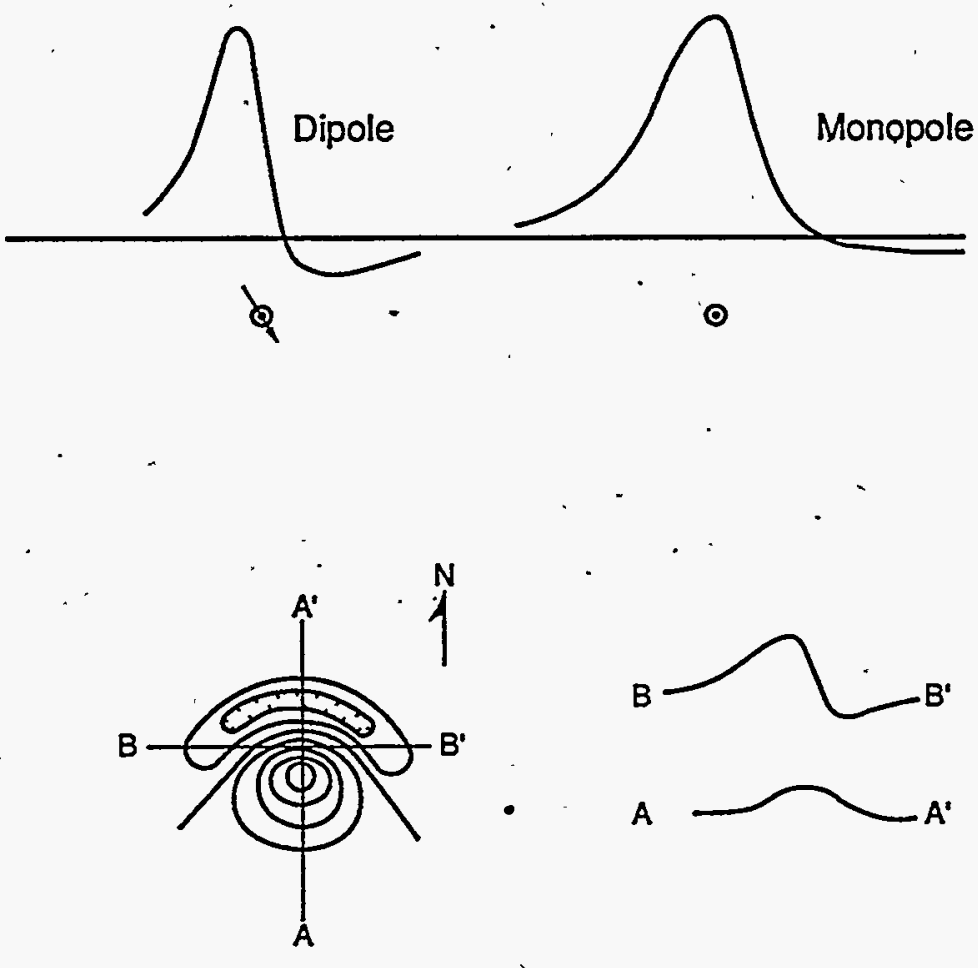

A

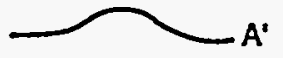

95X02292.05.AIL

Figure 5. Typical profiles of magnetic field intensity across a monopole and dipole for conditions similar to SRS. Also shown is a contour representation of magnetic field intensity over a dipole with accompanying representative profiles (adapted from Breiner, 1973). 

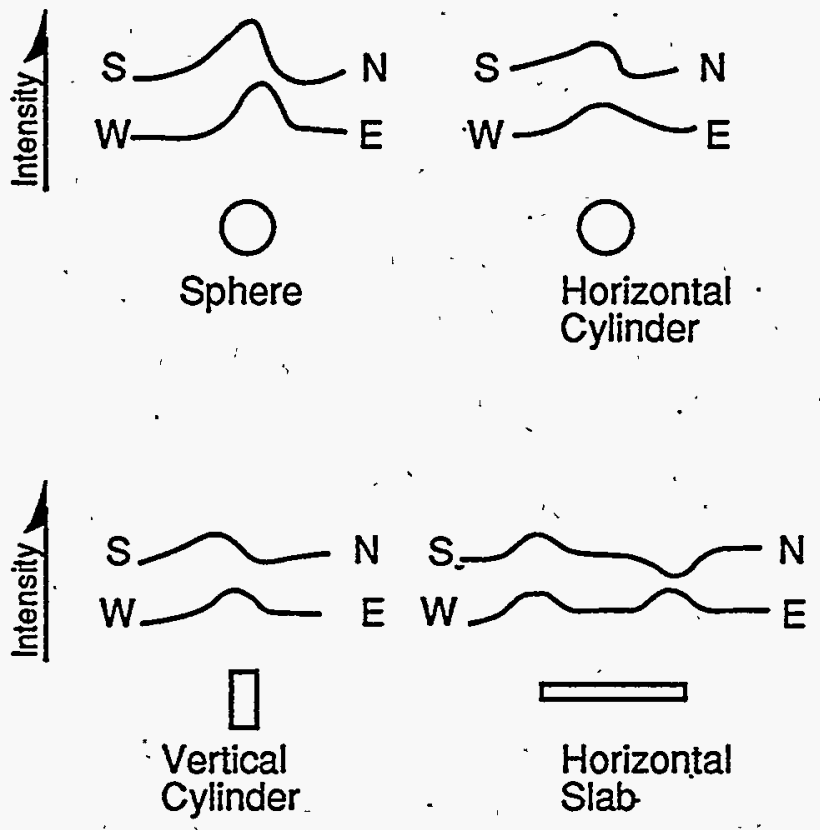

95X0229209.AlL

Figure 6. Magnetic intensity profiles across several geometric shapes of interest for magnetic field inclination similar to that of SRS (i.e. 60 degrees) (adapted from Breiner, 1973).
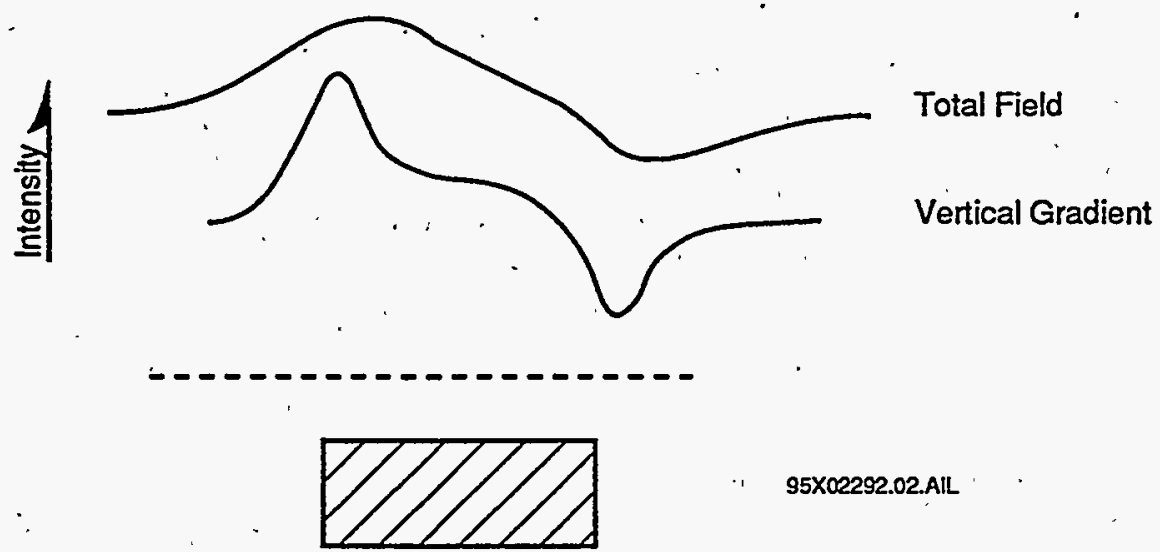

95X02292.02.AIL

Figure 7. The intensity of the total magnetic field compared with the vertical gradient over a prismatic body (adapted from Breiner, 1973). 


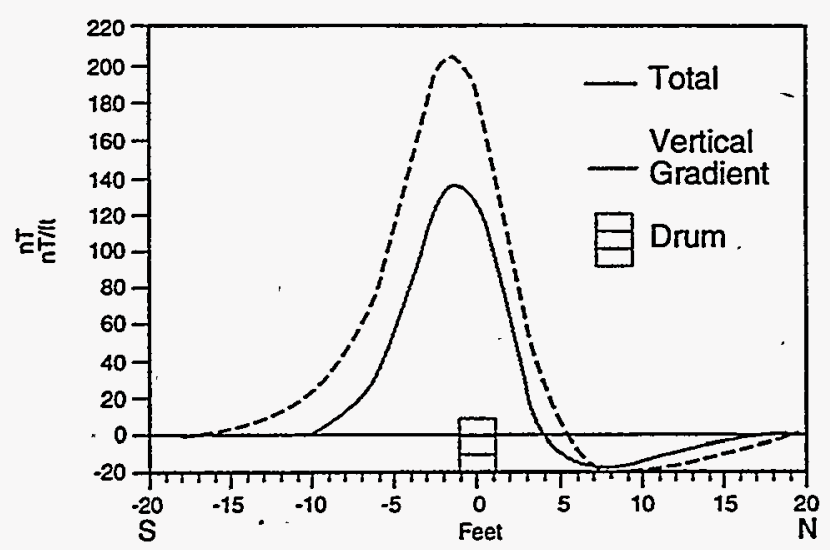

Single Drum

$(6 \mathrm{ft})$

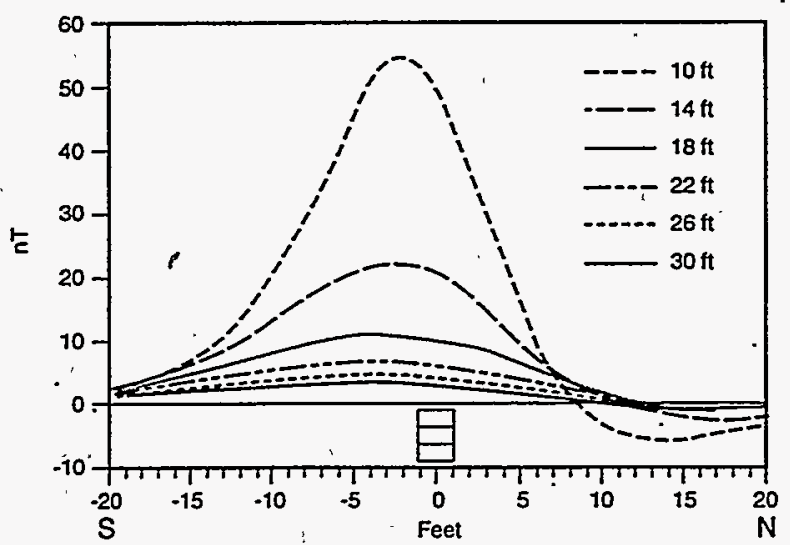

Total Field

Single Drum

(10-30 ft)

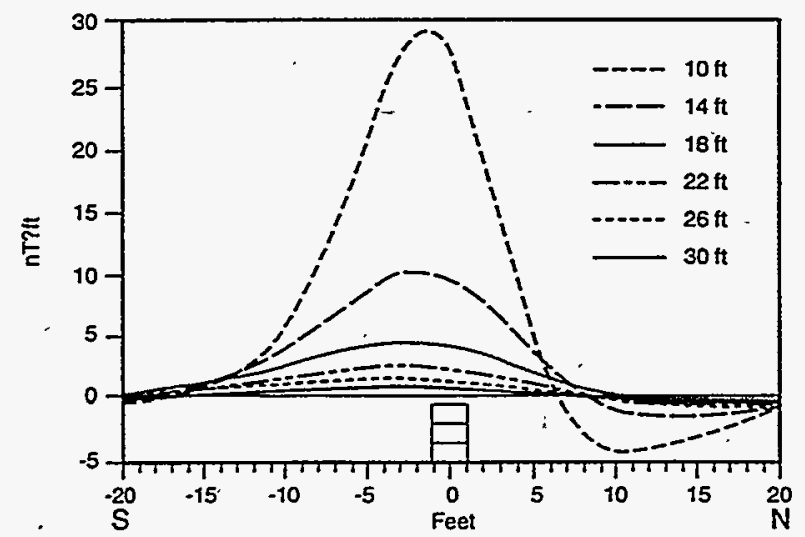

Gradient

95X02292.01.AIL

Single Drum

$(10-30 \mathrm{ft})$

Figure 8. Model total field and vertical gradient magnetic profiles for single 55-gallon steel drums in vertical position with the top at various distances below the sensor. Profiles calculated for a total field intensity of $53220 \mathrm{nT}$ and northern hemisphere inclination of 70 degrees (adapted from Gilkeson and others, 1990). 


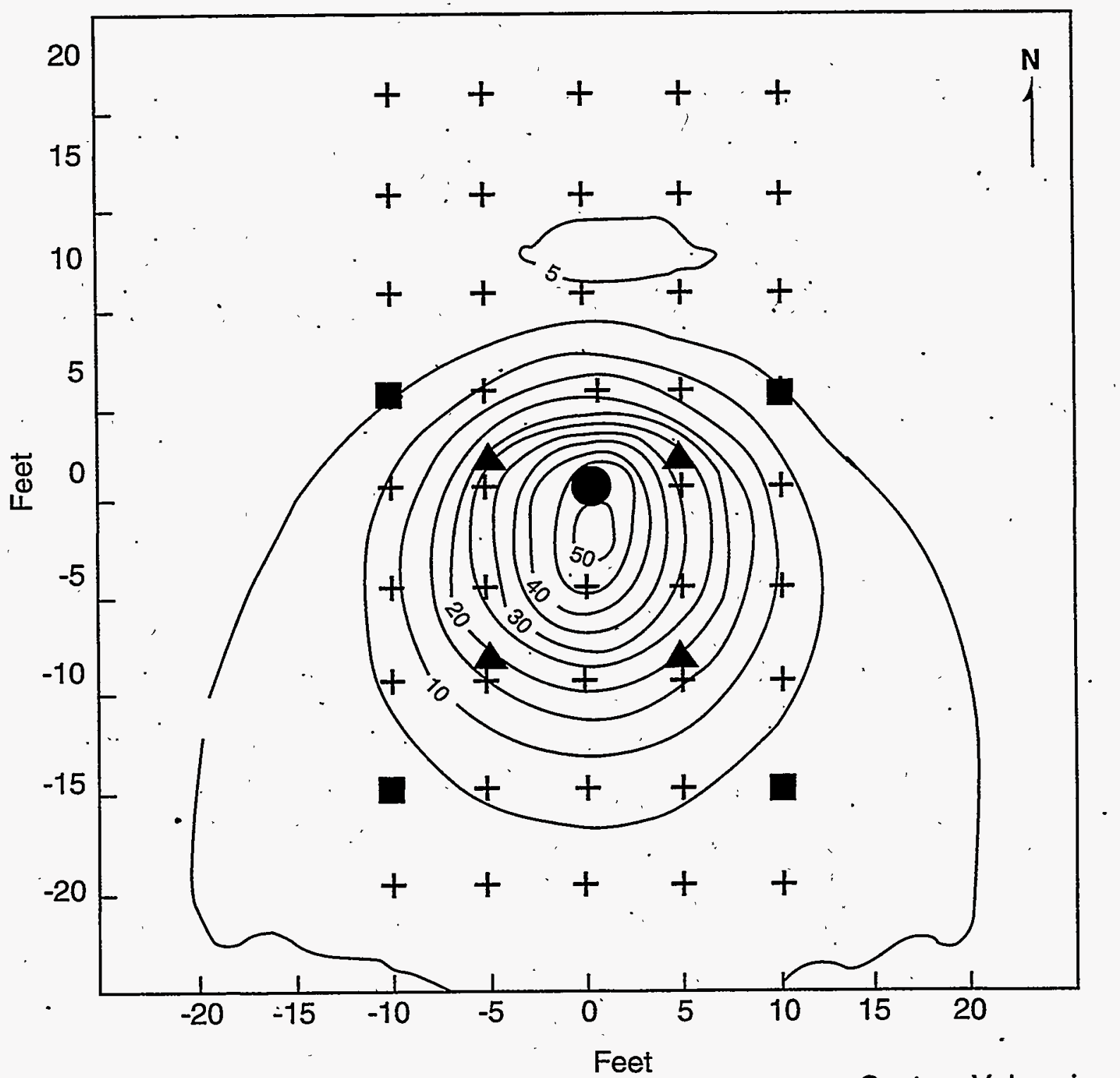

Contour Values in nt

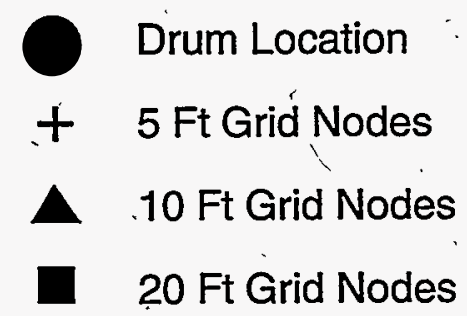

95X02292.04.AlL

Figure 9. Contour representation of total field anomaly calculated for a single 55-gallon steel drum in vertical position with the top $10 \mathrm{ft}$ below the sensor. Calculation based on a total field intensity of $53220 \mathrm{nT}$ and northern hemisphere inclination of 70 degrees (adapted from Gilkeson and others, 1990). 


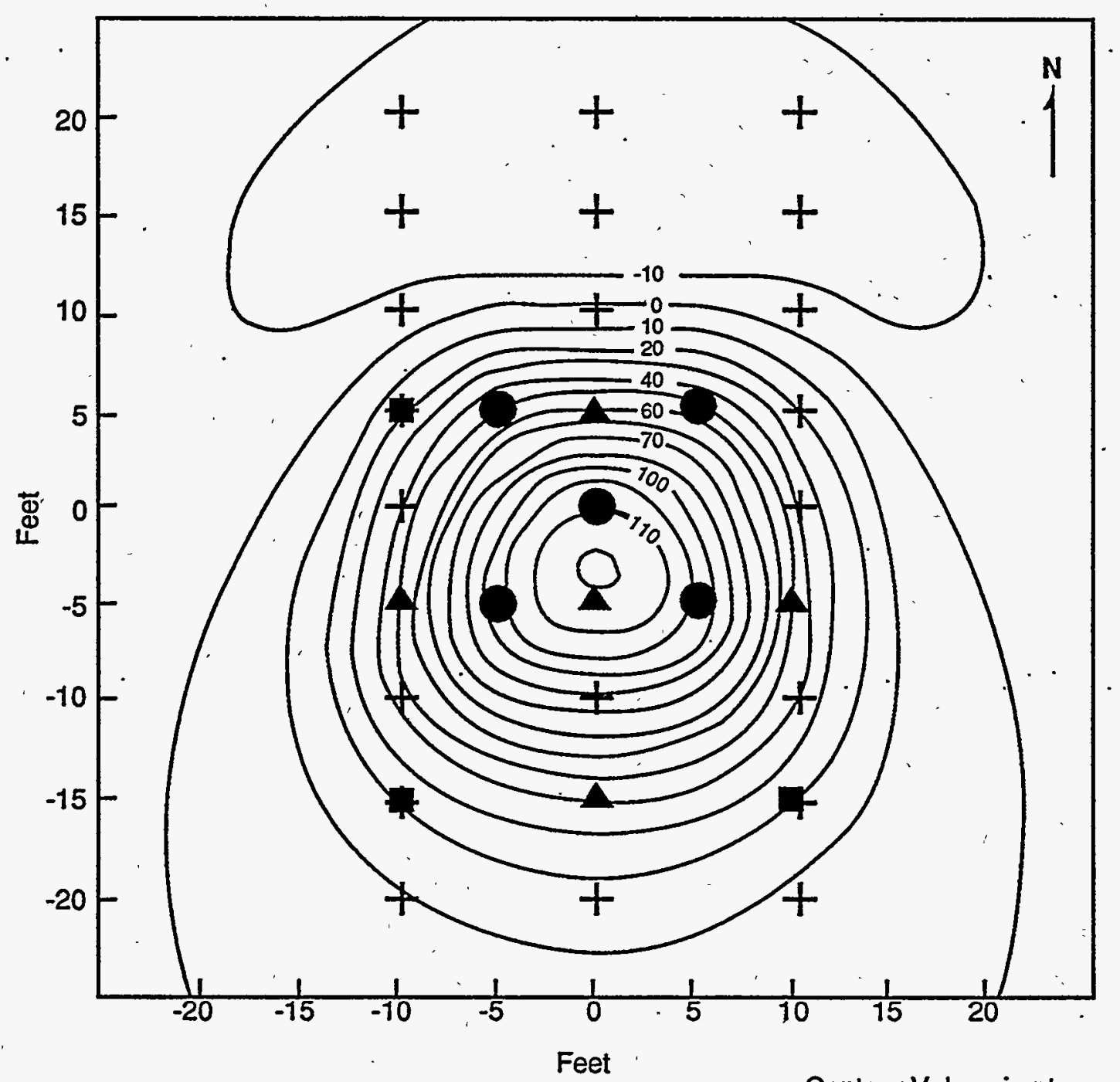

Contour Values in nt

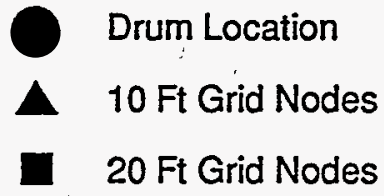

$95 \times 0229203 \mathrm{ALL}$

Figure 10. Contour representation of a cache of five steel 55-gallon drums in a 12-ft by 12-ft area with the top of the drums $10 \mathrm{ft}$ below the sensor. Calculation based on a total field intensity of $53220 \mathrm{nt}$ and northern hemisphere inclination of 70 degrees (adapted from Gilkeson and others, 1990). 


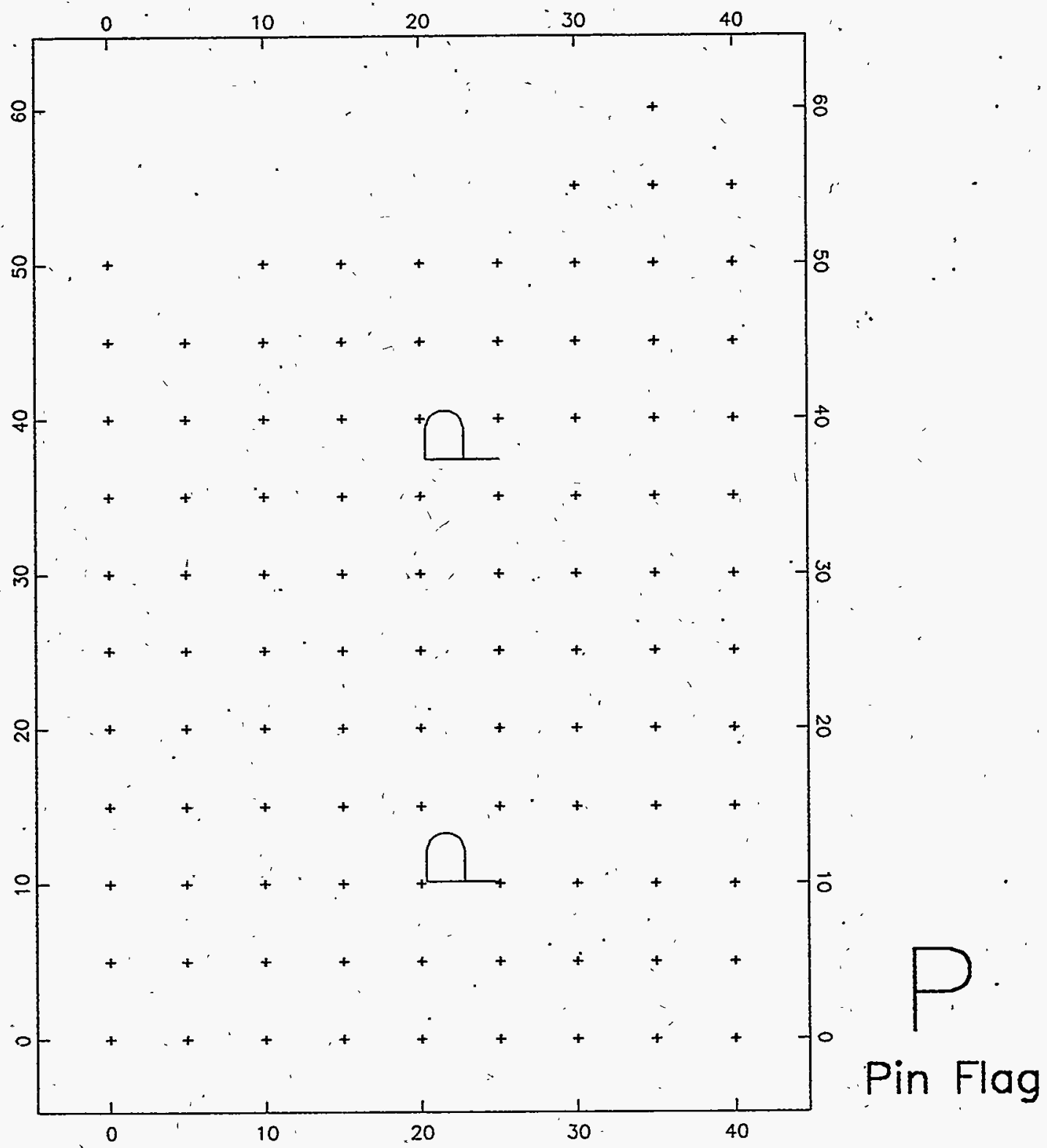

Risher Road Magnetic Survey STATION LOCATIONS
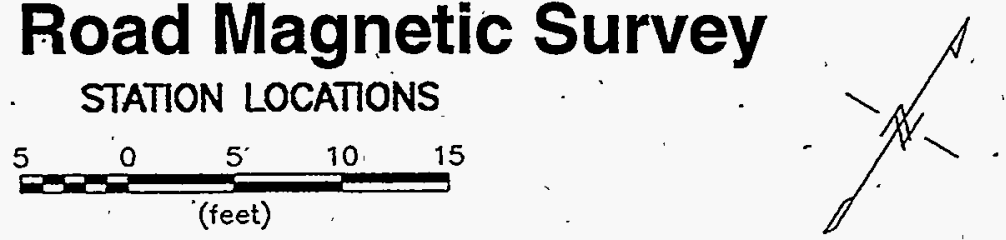

Figure 11. Planimetric map of the Risher Road Open Metal Pit Magnetic Survey Area. Station locations marked by " + ". 


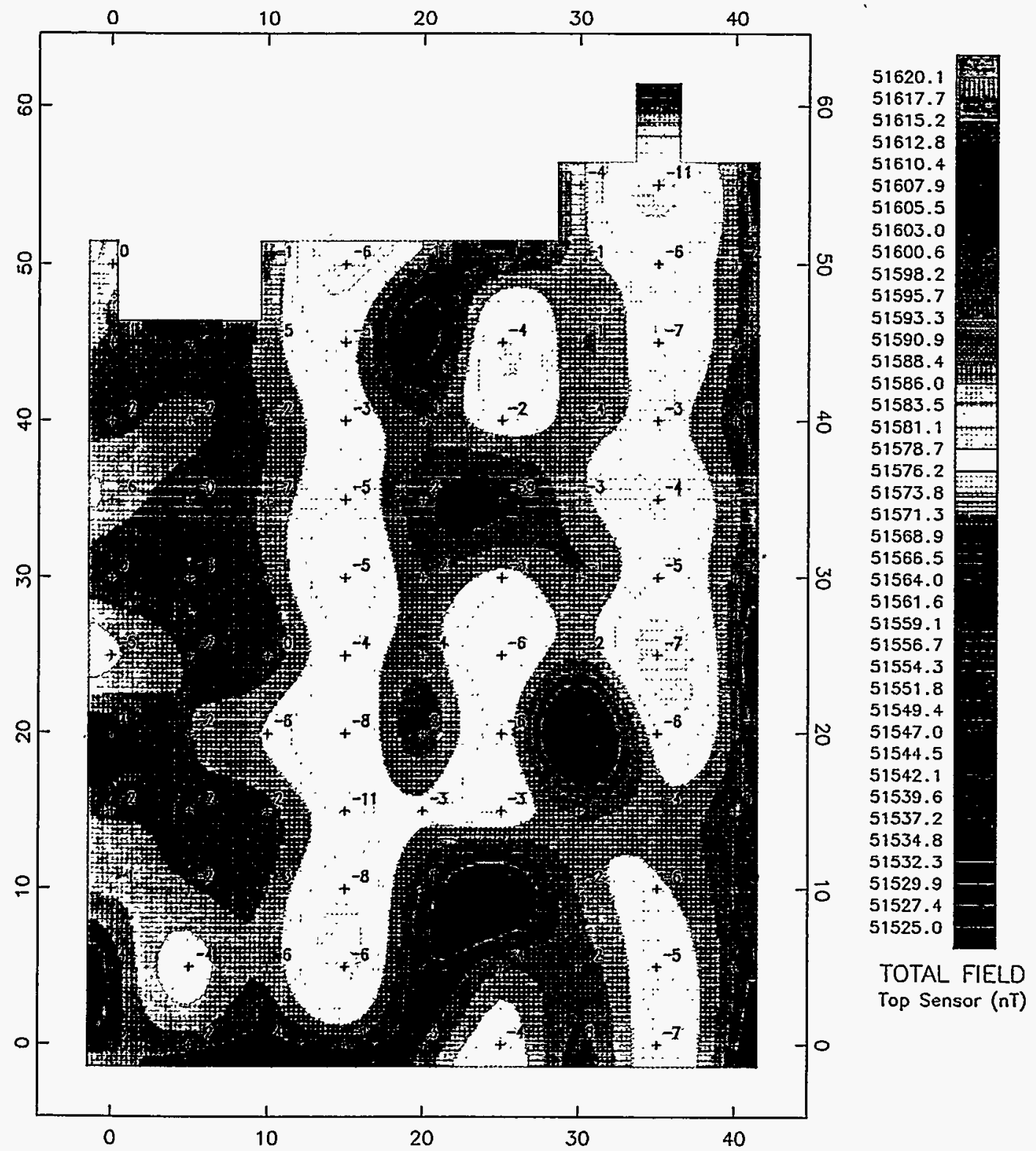

Risher Road Magnetic Survey

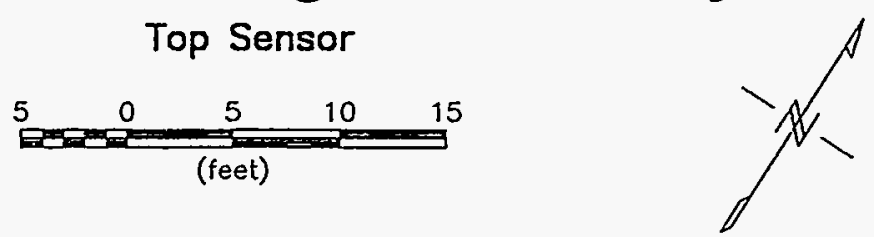

Figure 12. Color contour representation of top sensor ( $4 \mathrm{ft})$ magnetic survey data. 


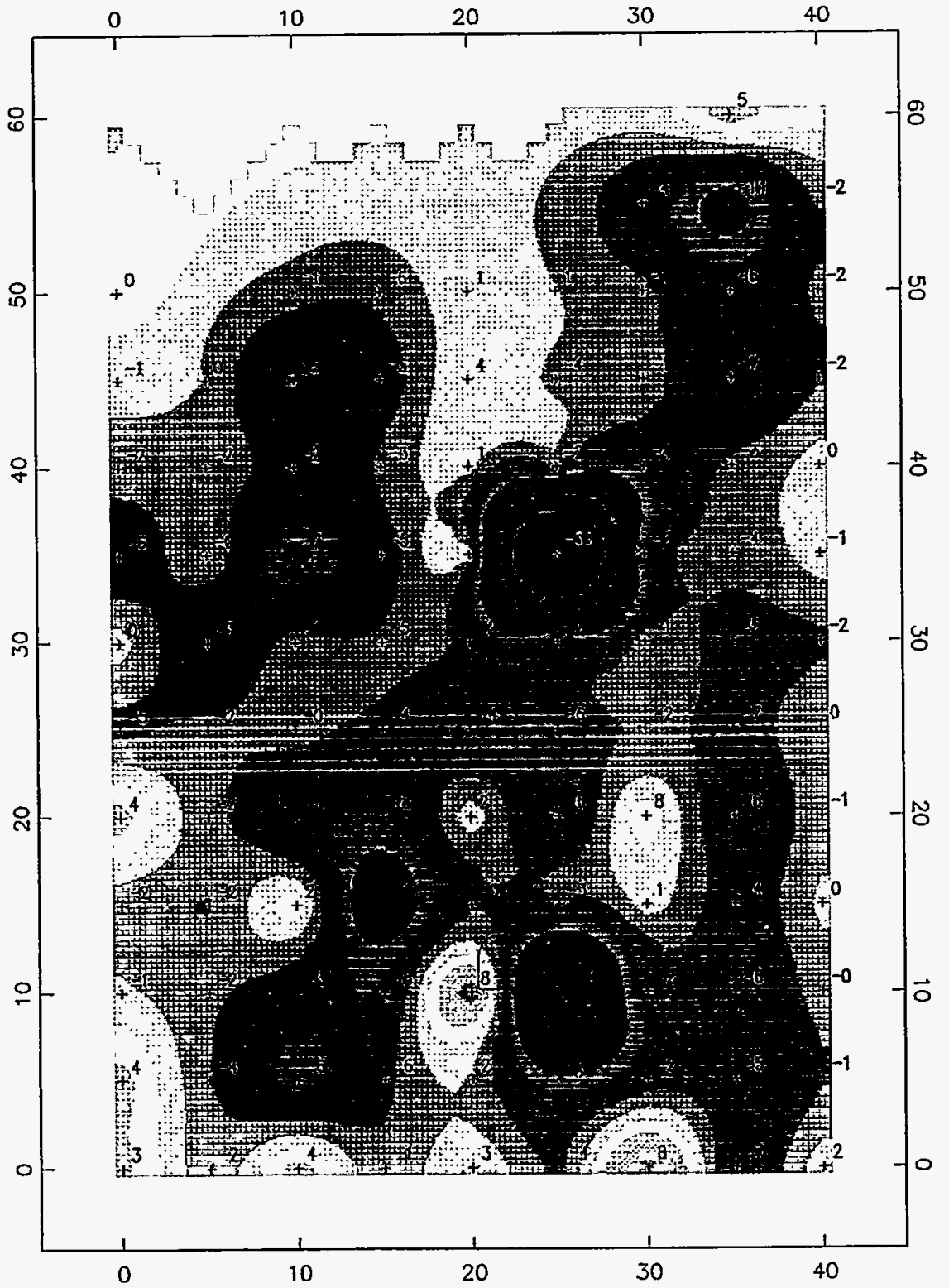

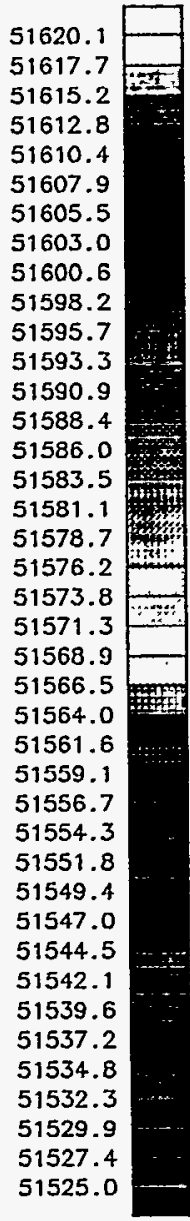

Total Field Bottom Sensor (nT)

\section{Risher Road Magnetic Survey}
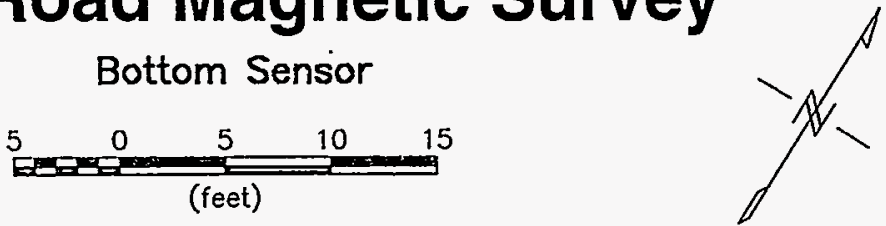

Figure 13. Color contoured representation of bottom sensor ( $2 \mathrm{ft}$ ) magnetic survey data. 


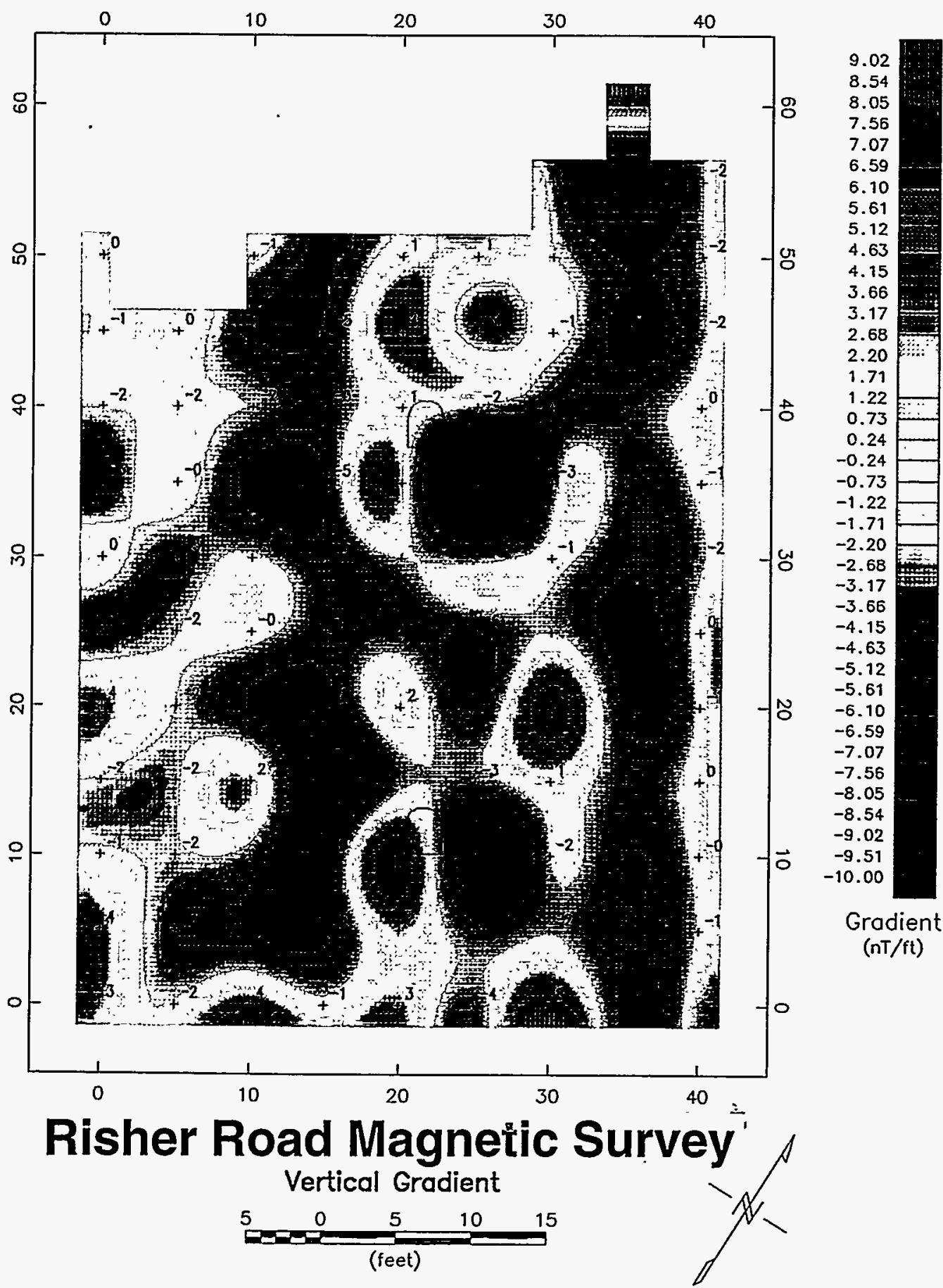

Figure 14. Color contoured representation of magnetic survey vertical gradient. 
This page intentionally left blank.

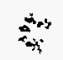




\section{Appendix A-Risher Road Magnetic Survey Diurnal Variations}





\section{Appendix A. Risher Road Magnetic Survey Diurnal Variations}

\begin{tabular}{|c|c|c|c|c|c|c|c|}
\hline & & TOP Senso & & & BOTT & OM Senso & \\
\hline Sta. & Time & Field (nT) & & Sta. & Time & Field (nT) & \\
\hline 1 & $13: 13: 27$ & 51566.3 & time:13:13:44 & 0 & $13: 13: 24$ & 51567.8 & time: $13: 13: 41$ \\
\hline 3 & $13: 13: 36$ & 51566.1 & mean: 51566.2 & 2 & $13: 13: 32$ & 51567.7 & mean: 51567.7 \\
\hline 5 & $13: 13: 44$ & 51566.2 & sd: 0.07 & 4 & $13: 13: 41$ & 51567.8 & sd: 0.08 \\
\hline 7 & $13: 13: 52$ & 51566.2 & & 6 & $13: 13: 49$ & 51567.7 & \\
\hline 9 & $13: 14: 00$ & 51566.2 & & 8 & $13: 13: 57$ & 51567.6 & \\
\hline 107 & $13: 30: 12$ & 51564.3 & time: $13: 30: 28$ & 106 & $13: 30: 09$ & 51569.6 & time: $13: 30: 25$ \\
\hline 109 & 13:30:20 & 51564.5 & mean: 51564.4 & 108 & $13: 30: 17$ & 51569.4 & mean: $\mathbf{5 1 5 6 9 . 4}$ \\
\hline 111 & $13: 30: 28$ & 51564.7 & sd: 0.18 & 110 & $13: 30: 25$ & 51571.5 & sd: $1: 38$ \\
\hline 113 & $13: 30: 36$ & 51564.3 & & 112 & $13: 30: 33$ & 51568.1 & \\
\hline 115 & 13:30:44 & 51564.3 & & 114 & $13: 30: 41$ & 51568.2 & \\
\hline 229 & $13: 48: 51$ & 51565.9 & time: $13: 49: 07$ & 228 & $13: 48: 48$ & 51566.2 & time: 13:49:04 \\
\hline 231 & $13: 48: 59$ & 51565.8 & mean: 51566.0 & 230 & $13: 48: 56$ & 51566.3 & mean: 51566.4 \\
\hline 233 & 13:49:07 & 51566.0 & sd: 0.16 & 232 & 13:49:04 & 51566.5 & sd: 0.18 \\
\hline 235 & $13: 49: 15$ & 51566.1 & & 234 & $13: 49: 12$ & 51566.6 & \\
\hline 237 & $13: 49: 23$ & 51566.2 & & 236 & 13:49:20 & 51566.6 & \\
\hline
\end{tabular}

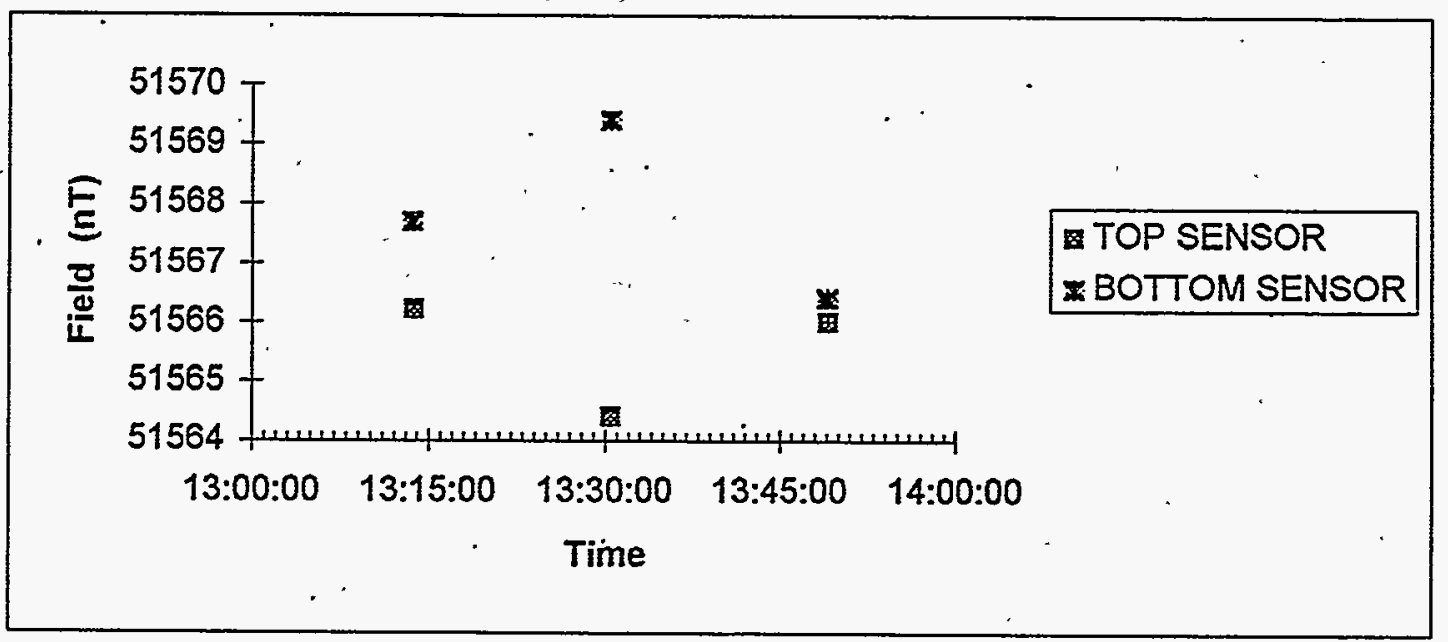


This page intentionally left blank. 


\section{Appendix B-Risher Road Magnetic Survey Data}





\begin{tabular}{|c|c|c|c|c|c|c|c|c|c|c|c|c|}
\hline \multirow[b]{2}{*}{ Line } & \multirow[b]{2}{*}{ Day } & \multirow[b]{2}{*}{ Time } & \multirow[b]{2}{*}{ Sta. } & \multirow[b]{2}{*}{$\mathbf{x}$} & \multirow[b]{2}{*}{$\mid Y$} & \multicolumn{3}{|c|}{ TOP Sensor (nT) } & \multicolumn{3}{|c|}{ BOTTOM Sensor (nT) } & \multirow{2}{*}{$\begin{array}{l}\text { Vert.Grad. } \\
\text { (nT/ft) }\end{array}$} \\
\hline & & & & & & uncorr. & corr. & diff. & uncorr. & corr. & diff. & \\
\hline 0 & 25 & 131433 & 10 & 40 & 0 & 51564.9 & 51565.0 & -0.1 & 51568.7 & 51568.6 & 0.1 & 1.9 \\
\hline 0 & .25 & 131443 & 12 & 40 & 5 & 51566.7 & 51566.8 & -0.1 & 51563.8 & 51563.7 & 0.1 & -1.4 \\
\hline 0 & 25 & 131453 & 14 & 40 & 10 & 51566.4 & 51566.5 & -0.1 & 51565.7 & 51565.6 & 0.1 & -0.4 \\
\hline 0 & 25 & 131504 & 16 & 40 & 15 & 51566.8 & 51566.9 & -0.1 & 51567.4 & 51567.3 & 0.1 & 0.3 \\
\hline 0 & 25 & 131514 & 18 & 40 & 20 & 51567.7 & 51567.9 & -0.2 & 51566.1 & 51565.9 & 0.2 & -0.8 \\
\hline 0 & 25 & 131524 & 20 & 40 & 25 & 51566.5 & 51566.7 & -0.2 & 51566.6 & 51566.4 & 0.2 & 0.1 \\
\hline 0 & 25 & 131534 & 22 & 40 & 30 & 51567.9 & 51568.1 & -0.2 & 51563.6 & 51563.4 & 0.2 & -2.2 \\
\hline 0 & 25 & 131544 & 24 & 40 & 35 & 51569.2 & 51569.4 & -0.2 & 51568.2 & 51568.0 & 0.2 & -0.5 \\
\hline 0 & 25 & 131553 & 26 & 40 & 40 & 51567.3 & 51567.5 & -0.2 & 51568.0 & 51567.8 & 0.2 . & 0.4 \\
\hline 0 & 25 & 131604 & 28 & 40 & 45 & 51568.2 & 51568.5 & -0.3 & 51563.9 & 51563.7 & 0.2 & -2.1 \\
\hline 0 & 25 & 131614 & 30 & 40 & 50 & 51569.0 & 51569.3 & -0.3 & 51565.1 & 51564.8 & 0.3 & -1.9 \\
\hline 0 & 25 & 131624 & 32 & 40 & 55 & 51568.6 & 51568.9 & -0.3 & 51564.5 & 51564.2 & 0.3 & -2.1 \\
\hline 1 & 25 & 131756 & 34 & 35 & 60 & 51563.9 & 51564.4 & -0.5 & 51573.8 & 51573.4 & 0.4 & 4.9 \\
\hline 1 & 25 & 131805 & 36 & 35 & 55 & 51576.2 & 51576.7 & -0.5 & 51553.6 & 51553.2 & 0.4 & -11.3 \\
\hline 1 & 25 & 131816 & 38 & 35 & 50 & 51573.2 & 51573.7 & -0.5 & 51561.3 & 51560.8 & 0.5 & -5.9 \\
\hline 1 & 25 & 131826 & 40 & 35 & 45 & 51573.4 & 51573.9 & -0.5 & 51559.3 & 51558.8 & 0.5 & -7.1 \\
\hline 1 & 25 & 131837 & 42 & 35 & 40 & 51571.7 & 51572.2 & -0.5 & 51564.9 & 51564.4 & 0.5 & -3.4 \\
\hline 1 & 25 & 131847 & 44 & 35 & 35 & 51573.4 & 51573.9 & -0.5 & $51564: 6$ & 51564.1 & 0.5 & -4.4 \\
\hline 1 & 25 & 131858 & 46 & 35 & 30 & 51573.1 & 51573.7 & -0.6 & 51562.6 & 51562.1 & 0.5 & -5.3 \\
\hline 1 & 25 & 131909 & 48 & 35 & 25 & 51578.0 & 51578.6 & -0.6 & 51563.7 & 51563.1 & 0.6 . & -7.2 \\
\hline 1 & 25 & 131920 & 50 & 35 & 20 & 51572.7 & 51573.3 & -0.6 & $51560.0^{\circ}$ & 51559.4 & -0.6 & -6.4 \\
\hline 1 & 25 & 131931 & 52 & 35 & 15 & 51569.8 & 51570.4 & -0.6 & 51562.5 & 51561.9 & 0.6 & -3.7 \\
\hline 1 & 25 & 131943 & 54 & 35 & 10 & 51571.1 & 51571.7 & -0.6 & 51560.0 & 51559.4 & 0.6 & -5.6 \\
\hline 1 & 25 & 131952 & 56 & 35 & 5 & 51572.3 & 51573.0 & -0.7 & 51561.5 & 51560.9 & 0.6 & -5.4 \\
\hline 1 & 25 & 132003 & 58 & 35 & 0 & 51572.9 & 51573.6 & -0.7 & 51559.9 & 51559.3 & 0.6 & -6.5 \\
\hline 2 & 25 & 132136 & 60 & 30 & 0 & 51565.1 & 51565.9 & -0.8 & 51581.6 & 51580.8 & 0.8 & 8.3 \\
\hline 2 & 25 & 132147 & 62 & 30 & 5 & 51566.6 & 51567.5 & -0.9 & 51562.9 & 51562.1 & 0.8 & -1.9 \\
\hline 2 & 25 & 132158 & 64 & 30 & 10 & 51568.2 & 51569.1 & -0.9 & 51564.9 & 51564.1 & 0.8 & -1.6 \\
\hline 2 & 25 & 132207 & 66 & 30 & 15 & 51567.3 & 51568.2 & -0.9 & 51568.8 & 51567.9 & 0.9 & 0.8 \\
\hline 2 & 25 & 132218 & 68 & 30 & 20 & 51556.3 & 51557.2 & -0.9 & 51572.0 & 51571.1 & 0.9 & 7.9 \\
\hline '2 & 25 & 132228 & 70 & 30 & 25 & 51568.2 & 69.1 & -0.9 & 51564.8 & 51563.9 & 0.9 & -1.7 \\
\hline 2 & 25 & 132238 & 72 & 30 & 30 & 51567.9 & 38.9 & -1.0 & 51566.8 & 51565.9 & 0.9 & -0.6 \\
\hline 2 & 25 & 132248 & 74 & 30 & 35 & 51569.5 & 51570.5 & -1.0 & 51562.9 & 51562.0 & 0.9 & -3.3 \\
\hline 2 & 25 & 132312 & 76 & 30 & 40 & 51569.4 & 51570.4 & -1.0 & 51561.4 & 51560.4 & 1.0 & -4 \\
\hline 2 & 25 & 132322 & 78 & 30 & 45 & 51567.9 & 51568.9 & -1.0 & 51566.8 & 51565.8 & 1.0 & $-0.6-$ \\
\hline 2 & 25 & 132332 & 80 & 30 & 50 & 51568.9 & 51570.0 & -1.1 & 51566.0 & 51565.0 & 1.0 & -1.5 \\
\hline 2 & 25 & 132341 & 82 & 30 & 55 & 51569.4 & 51570.5 & -1.1 & 51561.6 & 51560.6 & 1.0 & -3.9 \\
\hline 3 & 25 & 132811 & 84 & 25 & 50 & 51565.2 & 51566.8 & -1.6 & 51568.1 & 51566.6 & 1.5 & 1.5 \\
\hline 3 & 25 & 132818 & 86 & 25 & 45 & 51574.7 & 51576.3 & -1.6 & 51567.1 & 51565.6 & 1.5 & -3.8 \\
\hline 3 & 25 & 132826 & 88 & 25 & 40 & 51571.4 & 51573.0 & -1.6 & 51566.9 & 51565.4 & 1.5 & -2.3 \\
\hline 3 & 25 & 132835 & 90 & 25 & 35 & 51564.2 & 51565.8 & -1.6 & 51487.1 & 51485.6 & $1.5^{\prime}$ & -38.5 \\
\hline 3 & 25 & 132847 & 92 & 25 & 30 & 51570.7 & 51572.3 & -1.6 & 51564.5 & 51563.0 & 1.5 & -3.1 \\
\hline 3 & 25 & 132858 & 94 & 25 & 25 & 51574.1 & 51575.7 & -1.6 & 51562.9 & 51561.4 & 1.5 & -5.6 \\
\hline 3 & 25 & 132909 & 96 & 25 & 20 & 51571.7 & 51573.4 & -1.7 & 51559.6 & 51558.0 & 1.6 & -6 \\
\hline 3 & 25 & 132919 & 98 & 25 & 15 & 51572.1 & 51573.8 & -1.7 & 51566.2 & 51564.6 & 1.6 & -3 \\
\hline 3 & 25 & 132930 & 100 & 25 & 10 & 51559.1 & 51560.8 & -1.7 & 51530.8 & 51529.2 & 1.6 & -14.2 \\
\hline 3 & 25 & 132941 & 102 & 25 & 5 & 51566.7 & 51568.4 & -1.7 & 51558.6 & 51557.0 & 1.6 & -4 \\
\hline
\end{tabular}




\begin{tabular}{|c|c|c|c|c|c|c|c|c|c|c|c|c|}
\hline \multirow{2}{*}{ Line } & \multirow[b]{2}{*}{ Day } & \multirow[b]{2}{*}{ Time } & \multirow[b]{2}{*}{ Sta. } & \multirow[b]{2}{*}{$\mathbf{x}$} & \multirow[b]{2}{*}{$\mathbf{Y}$} & \multicolumn{3}{|c|}{ TOP Sensor (nT) } & \multicolumn{3}{|c|}{ BOTTOM Sensor (nT) } & \multirow{2}{*}{$\begin{array}{c}\text { Vert.Grad. } \\
\text { (nT/ft) }\end{array}$} \\
\hline & & & & & & uncorr. & ,corr. & diff. & & corr. & diff. & \\
\hline 3 & 25 & 132951 & 104 & 25 & 0 & 51571.8 & 51573.5 & -1.7 & 51564.6 & 51563.0 & 1.6 & -3.6 \\
\hline 4 & 25 & 133234 & 116 & 20 & 0 & 51564.8 & 51566.4 & -1.6 & 51570.6 & 51569.3 & 1.3 & 2.9 \\
\hline 4 & 25 & 133245 & 118 & 20 & 5 & 51563.2 & 51564.8 & -1.6 & 51567.6 & 51566.3 & 1.3 & 2.2 \\
\hline 4 & 25 & 133255 & 120 & 20 & 10 & 51565.0 & 51566.6 & -1.6 & 51581.8 & 51580.5 & 1.3 & 8.4 \\
\hline 4 & 25 & 133305 & 122 & 20 & 15 & 51570.1 & 51571.7 & -1.6 & 51565.0 & 51563.7 & 1.3 & -2.6 \\
\hline 4 & 25 & 133314 & 124 & 20 & 20 & 51565.8 & 51567.4 & -1.6 & 51569.7 & 51568.4 & 1.3 & 1.9 \\
\hline 4 & 25 & 133323 & 126 & 20 & 25 & 51568.4 & 51569.9 & -1.5 & 51561.3 & 51560.1 & 1.2 & -3.6 \\
\hline 4 & 25 & 133333 & 128 & 20 & 30 & 51567.7 & 51569.2 & -1.5 & 51564.5 & 51563.3 & 1.2 & -1.6 \\
\hline 4 & 25 & 133343 & 130 & 20 & 35 & 51565.7 & 51567.2 & -1.5 & 51569.6 & 51568.4 & 1.2 & 2 \\
\hline 4 & 25 & 133357 & 132 & $20^{\circ}$ & 40 & 51567.6 & 51569.1 & -1.5 & 51568.7 & 51567.6 & 1.1 & 0.5 \\
\hline 4 & 25 & 133410 & 134 & 20 & 45 & 51560.9 & 51562.4 & -1.5 & 51569.7 & 51568.6 & 1.1 & 4.4 \\
\hline 4 & 25 & 133421 & 136 & 20 & 50 & 51566.9 & 51568.4 & -1.5 & 51569.1 & 51568.0 & 1.1 & 1.1 \\
\hline 5 & 25 & 133558 & 138 & 15 & 50 & 51577.9 & 51579.2 & -1.3 & 51565.5 & 51564.7 & 0.8 & -6.2 \\
\hline 5 & 25 & 133609 & 140 & 15 & 45 & 51571.8 & 51573.1 & -1.3 & 51562.2 & 51561.4 & 0.8 & -4.8 \\
\hline 5 & 25 & 133620 & 142 & 15 & 40 & 51571.7 & 51573.0 & -1.3 & 51565.2 & 51564.4 & 0.8 & -3.3 \\
\hline 5 & 25 & 133630 & 144 & 15 & 35 & 51572.2 & 51573.5 & -1.3 & 51562.3 & 51561.6 & 0.7 & -4.9 \\
\hline 5 & 25 & 133640 & 146 & 15 & 30 & 51574.6 & 51575.9 & -1.3 & 51565.0 & 51564.3 & 0.7 & -4.8 \\
\hline 5 & 25 & 133652 & 148 & 15 & 25 & 51572.1 & 51573.4 & -1.3 & 51564.0 & 51563.3 & 0.7 & -4.1 \\
\hline 5 & 25 & 133702 & 150 & 15 & 20 & 51574.5 & 51575.7 & -1.2 & 51559.3 & 51558.7 & 0.6 & -7.6 \\
\hline 5 & 25 & 133713 & 152 & 15 & 15 & 51572.1 & 51573.3 & -1.2 & 51549.5 & 51548.9 & 0.6 & -11.3 \\
\hline 5 & 25 & 133724 & 154 & 15 & 10 & 51574.6 & 51575.8 & -1.2 & 51559.6 & 51559.0 & 0.6 & -7.5 \\
\hline 5 & 25 & 133734 & 156 & 15 & 5 & 51576.4 & 51577.6 & -1.2 & 51563.8 & 51563.2 & 0.6 & -6.3 \\
\hline 5 & 25 & 133748 & 158 & 15 & 0 & 51566.4 & 51567.6 & -1.2 & 51564.5 & 51564.0 & 0.5 & -1 \\
\hline 6 & 25 & 133917 & 160 & 10 & 0 & 51564.6 & 51565.6 & -1.0 & 51573.5 & 51573.2 & 0.3 & 4.4 \\
\hline 6 & 25 & 133927 & 162 & 10 & 5 & 51568.4 & 51569.4 & -1.0 & 51557.2 & 51556.9 & 0.3 & -5.6 \\
\hline 6 & 25 & 133936 & .164 & 10 & 10 & 51567.9 & 51568.9 & -1.0 & $51561: 8$ & 51561.6 & 0.2 & -3.1 \\
\hline 6 & 25 & 133946 & 166 & 10 & 15 & 51567.2 & 51568.2 & -1.0 & 51571.6 & 51571.4 & 0.2 & 2.2 \\
\hline 6 & 25 & 133956 & 168 & 10 & 20 & 51570.7 & 51571.7 & -1.0 & 51559.3 & 51559.1 & 0.2 & -5.7 \\
\hline 6 & 25 & 134007 & 170 & 10 & 25 & 51566.5 & 51567.5 & -1.0 & 51565.6 & 51565.4 & 0.2 & -0.4 \\
\hline 6 & 25 & 134016 & 172 & 10 & 30 & 51567.9 & 51568.9 & -1.0 & 51565.5 & 51565.4 & 0.1 & -1.2 \\
\hline 6 & 25 & 134026 & 174 & 10 & 35 & 51568.5 & 51569.4 & -0.9 & 51554.7 & 51554.6 & 0.1 & -6.9 \\
\hline 6 & 25 & 134035 & 176 & 10 & 40 & 51568.0 & 51568.9 & -0.9 & 51564.3 & 51564.2 & 0.1 & -1.9 \\
\hline 6 & 25 & 134044 & 178 & 10 & 45 & 51569.1 & 51570.0 & -0.9 & 51558.2 & 51558.1 & 0.1 & -5.5 \\
\hline 6 . & 25 & 134053 & 180 & 10 & 50 & 51567.3 & 51568.2 & -0.9 & 51565.3 & 51565.3 & 0.0 & -1 \\
\hline 7 & 25 & 134219 & 182 & 5 & 45 & 51565.8 & 51566.6 & -0.8 & 51566.3 & 51566.5 & -0.2 & 0.3 \\
\hline 7 & 25 & 134229 & 184 & 5 & 40 & 51568.5 & 51569.3 & -0.8 & 51565.5 & 51565.7 & -0.2 & -1.5 \\
\hline 7 & 25 & 134239 & 186 & 5 & 35 & 51567.1 & 51567.9 & -0.8 & 51566.5 & 51566.8 & -0.3 & -0.3 \\
\hline 7 & 25 & 134248 & 188 & 5 & 30 & 51566.4 . & 51567.1 & -0.7 & 51559.7 & 51560.0 & -0.3 & -3.4 \\
\hline 7 & 25 & 134258 & 190 & 5 & 25 & 51567.8 & 51568.5 & -0.7 & 51564.2 & 51564.5 & -0.3 & -1.8 \\
\hline 7 & 25 & 134307 & 192 & 5 & 20 & 51568.1 & 51568.8 & -0.7 & 51564.5 & 51564.8 & -0.3 & -1.8 \\
\hline 7 & 25 & 134316 & 194 & 5 & 15 & 51567.7 & 51568.4 & -0.7 . & 51563.3 & 51563.7 & -0.4 & -2.2 \\
\hline 7 & 25 & 134325 & 196 & 5 & 10 & 51568.4 & 51569.1 & -0.7 & 51564.3 & 51564.7 & -0.4 & -2.1 \\
\hline 7 & 25 & 134334 & 198 & 5 & 5 & 51571.8 & 51572.5 & -0.7 & 51563.7 & 51564.1 & -0.4 & -4.1 \\
\hline 7 & 25 & 134344 & 200 & 5 & 0 & 51566.9 & 51567.6 & -0.7 & 51563.8 & 51564.2 & -0.4 & -1.6 \\
\hline 8 & 25 & 134522 & 202 & 0 & 0 & 51565.6 & 51566.1 & -0.5 & 51571.4 & 51572.1 & -0.7 & 2.9 \\
\hline 8 & 25 & 134531 & 204 & 0. & 5 & 51564.5 & 51565.0 & -0.5 & 51571.9 & 51572.6 & -0.7 & 3.7 \\
\hline 8 & 25 & 134542 & 206 & 0 & 10 & 51568.8 & 51569.3 & -0.5 & 51566.4 & 51567.1 & -0.7 & -1.2 \\
\hline 8 & 25 & 134551 & 208 & 0 & 15 & 51567.9 & 51568.4 & -0.5 & 51563.6 & 51564.4 & -0.8 & -2.2 \\
\hline 8 & 25 & 134600 & 210 & 0 & $20 \mid$ & 51564.7 & 51565.2 & -0.5 & 51572.1 & 51572.9 & -0.8 & 3.7 \\
\hline
\end{tabular}




\begin{tabular}{|c|c|c|c|c|c|c|c|c|c|c|c|c|}
\hline \multirow{2}{*}{ Line } & \multirow[b]{2}{*}{ Day } & \multirow[b]{2}{*}{ Time } & \multirow[b]{2}{*}{ Sta. } & \multirow[b]{2}{*}{$\mathbf{x}$} & \multirow[b]{2}{*}{$\mathbf{Y}$} & \multicolumn{3}{|c|}{ TOP Sensor (nT) } & \multicolumn{3}{|c|}{ BOTTOM Sensor (nT) } & \multirow{2}{*}{$\begin{array}{c}\text { Vert.Grad. } \\
\text { (nT/ft) }\end{array}$} \\
\hline & & & & & & uncorr. & corr. & diff. & uncorr. & corr. & diff. & \\
\hline 8 & 25 & 134609 & 212 & 0 & 25 & 51571.4 & 51571.9 & -0.5 & 51562.0 & 51562.8 & -0.8 & -4.7 \\
\hline ' 8 & 25 & 134617 & 214 & 0 & 30 & 51566.6 & 51567.0 & -0.4 & 51567.1 & 51567.9 & -0.8 & 0.3 \\
\hline 8 & 25 & 134626 & 216 & 0 & 35 & 51570.2 & 51570.6 & -0.4 & 51559.2 & 51560.1 & -0.9 & -5.5 \\
\hline 8 & 25 & 134635 & 218 & 0 & 40 & 51567.7 & 51568.1 & -0.4 & 51564.5 & 51565.4 & -0.9 & -1.6 \\
\hline 8 & 25 & 134645 & 220 & 0 & 45 & 51567.8 & 51568.2 & -0.4 & 51566.2 & 51567.1 & -0.9 & -0.8 \\
\hline 8 & 25 & 134654 & 222 & 0 & 50 & 51569.0 & $51569: 4$ & -0.4 & 51569.7 & 51570.6 & -0.9 & 0.4 \\
\hline 666 & 25 & 134731 & 224 & -5 & 0 & 51567.2 & 51567.5 & -0.3 & 51564.5 & 51565.5 & -1.0 & -1.4 \\
\hline 777 & 25 & 134820 & 226 & -10 & 0 & 51566.0 & 51566.3 & -0.3 & 51557.9 & 51559.1 & -1.2 & -4 \\
\hline
\end{tabular}


